\title{
Feminism and 'The Family'
}

\author{
Lesley Caldwell
}

The Anti-social Family, Michèle Barrett and Mary McIntosh Verso Editions 1982 ISBN 0-86091-75-7, £3.95 164 pages

Patriarchal Precedents, Rosalind Coward Routledge and Kegan Paul 1983 ISBN 0-7100-9324 £4.95326 pages

What is to be done about the family? Lynne Segal (Ed), Penguin Books $£ 2.50237$ pages

Rethinking the Family, Barrie Thorne and Marilyn Yalom (Eds) Longmans 1982 ISBN 0-582-28265-9 $£ 5.95246$ pages

The family is the institution that has been consistently singled out as central for any understanding of patterns of sexed domination and subordination. The range of issues about the family explored in these books bears testimony to the liveliness and committedness of feminist debate on the subject. This set of texts and the debates they engage with are indicative of a fairly extended recognition within the left that questions of sexual identity, of different forms of domestic arrangement, of state regulation of an allegedly private arena, of questions regarding motherhood, and concepts of the child and her/his rights have a particular political weight in advanced capitalist countries in the eighties.

These are issues traditionally organized around dominant conceptions of 'the family'. My suspicion is that it is still feminists who do most of the work of reopening and extending these issues, though socialist debate has taken them up with a welcome seriousness. However, Ros Coward's carefully argued chapters on Marxism and the family put paid to any idea that, in itself, this concern is a new one. And she also makes the important point that such a concern, detached from any consideration of the ways it is presented and struggled for, does not necessarily lead to real political gains, concretely manifested. Nonetheless what the books do register is a highly increased visibility of certain questions and approaches, a visibility moreover that is not confined to the arena of socialist and/or feminist discussion. For one of the aspects with which these books attempt to engage is the processes of redefinition of the so-called private through the proliferation of books, statements, policies and ideologies about 'the family' that are evident in the media and in institutional, especially legal practices in England and the USA in the past decade.

These processes are seen as linked, in a variety of ways, to the impact of Feminist Review No16, April 1984 
Thatcherism in Great Britain and to certain conservatisms in the USA. This means that the topics discussed here are part of a wider set of considerations than those of contemporary feminism alone. The nexus of issues regarding relations between the sexes and the generations has become part of a more official political arena and part of a more diffused societal concern.

There is no space here to expand on this history but so far as these connexions are examined, I think this presents the least satisfying aspects of these books. This is partly a matter of the form of the books since they are for the most part short, so that there is not enough space to investigate assumed connexions, for instance the relation between economic and family policies, or the relation between economic recession and the grip of conservative ideologies, in any real detail. Partly, however, it is a question of approach in that it is often argued, implicitly or explicitly that these connexions can be made and need to be made in a relatively unproblematic way. I shall be suggesting that this is not the case.

Two of these books are collections of articles, one (Thorne and Yalom 1982) originally a set of public lectures on the family presented at Stanford University in 1979, the other (Segal 1983) a more 'popular' intervention into the Great Britain of the eighties. Barrett and McIntosh's book shares certain features of both and it emerges very much from the same context as the latter collection. The book by Rosalind Coward also lays claims to being read as an intervention in recent feminist debates but its orientation is far more scholarly. Even a cursory examination of their lists of contents exposes the degree to which 'the family' or even 'family forms' is a shorthand for discussion of a multiplicity of different issues with quite different parameters and quite different problems. In attempting to deal in any way at all with all four books together, I can only point to some of the themes explored and touch on some aspects that direct attention to the contexts in which it has become possible for the range of practices, histories and policies described here to be presented together.

What constitutes the political and to what extent feminism has assisted in redefining its boundaries for the left, is one of the problematic issues arising from all these books. Each of them in its mode of presentation, its style, the issues chosen for discussion and its overtly claimed feminism establishes an intended audience/ audiences. But despite the situations from which they emerge and the very different projects they see themselves as representing, I feel that there is a considerable degree of overlap in their potential readership. This in turn relates to the kinds of politics they are investigating. The collection edited by Lynne Segal, the most recent and most consciously interventionist, contains articles that describe, rethink and reassess particular approaches that have developed through the women's liberation movement in Great Britain. These articles take as their terrain of manoeuvre the discourses of contemporary feminism. They ask how we, as feminists, engage with and question some of the earlier choices made, as regards areas of work and ways of living. How do we live and work differently? What assessments do we make of our recent histories? How do we see a politics of living differently - both publicly and domestically continuing in the present, in the light of the very different external realities of the eighties and the experience of the gains and losses of the sixties and seventies?

The collection is organized around a series of important theoretical and political concerns - waged work and 'reproductive' labour, state policies and state regulation, childcare facilities, questions of sexual preferences and modes of living - together with an attempt to place these alongside very different official political concerns with different sets of priorities. But the focus here is primarily on issues that can be linked to the concerns and lifestyles of feminist women. The central problems looked at are those of how to live and with whom, how to approach (or not) the realities of shared parenting and/or collectivized childcare, how to continue to grapple with these as 
daily problems when the discrepancies between political aspirations and individual needs and desires become apparent.

Such an emphasis is partially present too, in The Anti-social Family, especially in chapters one and four. However, although the book argues strongly for flexibility and variety, I feel that it over-stresses the need to understand the dominance of traditional familial models and ways of thinking, at the expense of spending more time presenting the more 'flexible' ways of living that the authors want to endorse. This is especially the case with their attention to the possible hetero-sexism that their approach could be seen as supporting. While they are anxious to acknowledge the oppressiveness of the dominant idea of the heterosexual family form to both gays and to people who choose to live alone, their own emphases primarily single out the institution of marriage as the institution to resist. Of course, they are arguing that the privileging of a particular form of heterosexual relationship establishes a hierarchy that is confirmed and consolidated through a range of policies and laws and contributes to the pervasive familialization of which they speak. But I do not think they give sufficient attention to the alternatives they present. The middle chapters offer an account of some of the literature on the family and women, together with detailed critiques of two influential texts by Donzelot and Lasch. The chapters aim to dispute these accounts and in so doing move beyond the kinds of questions that form the major orientation of the Segal volume.

The American collection edited by Thorne and Yalom, despite the fact that it reproduces an academic seminar series around the theme of the family, exhibits a concern with a similar set of issues. There are general articles on the family, and feminist emphases about it, on the links between home and work, on the relation between family and (welfare) state, on mothering, on the law, and on the differing class/gender based experiences within households, all of which may also be found in the books by the English feminists. Any discussion of birth control is an interesting absence in the Segal collection. The American collection does contain an article on contraception that raises some pertinent questions about the changing historical forms and emphases of the feminisms. There are also two articles written by men, one on the links that have been drawn between maternal responsibility and mental illness and one organized around the idea of male roles and the process of their renegotiation towards a greater equality.

Some of the articles included operate within a framework that admits of the possibility of achieving equality and provides a defence of forms of individualism (Spiegel, Prager, Goode). Others depend on varieties of Marxist accounts (Gordon, Rapp and Zaretsky particularly). The authors also argue, as do Segal, and Barrett and McIntosh, for attention to the pro-family policies and movements that have achieved more success in the USA than they have here. In other words they select certain features that appear to parallel the way the discursive arena of the family is established, that is, what it is we are speaking of when we speak of the family.

The authors argue that their scope is a political one, but the way they choose to discuss these issues often, though not always, employs a more detached language; they more often inhabit the territory of conventional social science. This collection is by and large less concerned with how we live, and more with academic accounts of issues that impinge upon and describe how we live. For instance, a comparison of the articles by Prager and Bennett (in Segal) reveals a common concern with the development of aspects of the law as it relates to families and distribution and allocation of resources to/within them. But there the similarities stop. The piece by Bennett focuses its concern through constant reference to the campaigns, priorities and choices of the feminist movement on the one hand while also stressing the problems involved in a practical campaigning, demand-orientated politics of social policy. It gives a sense of work in progress and work at a series of different levels. It is work that derives from, 


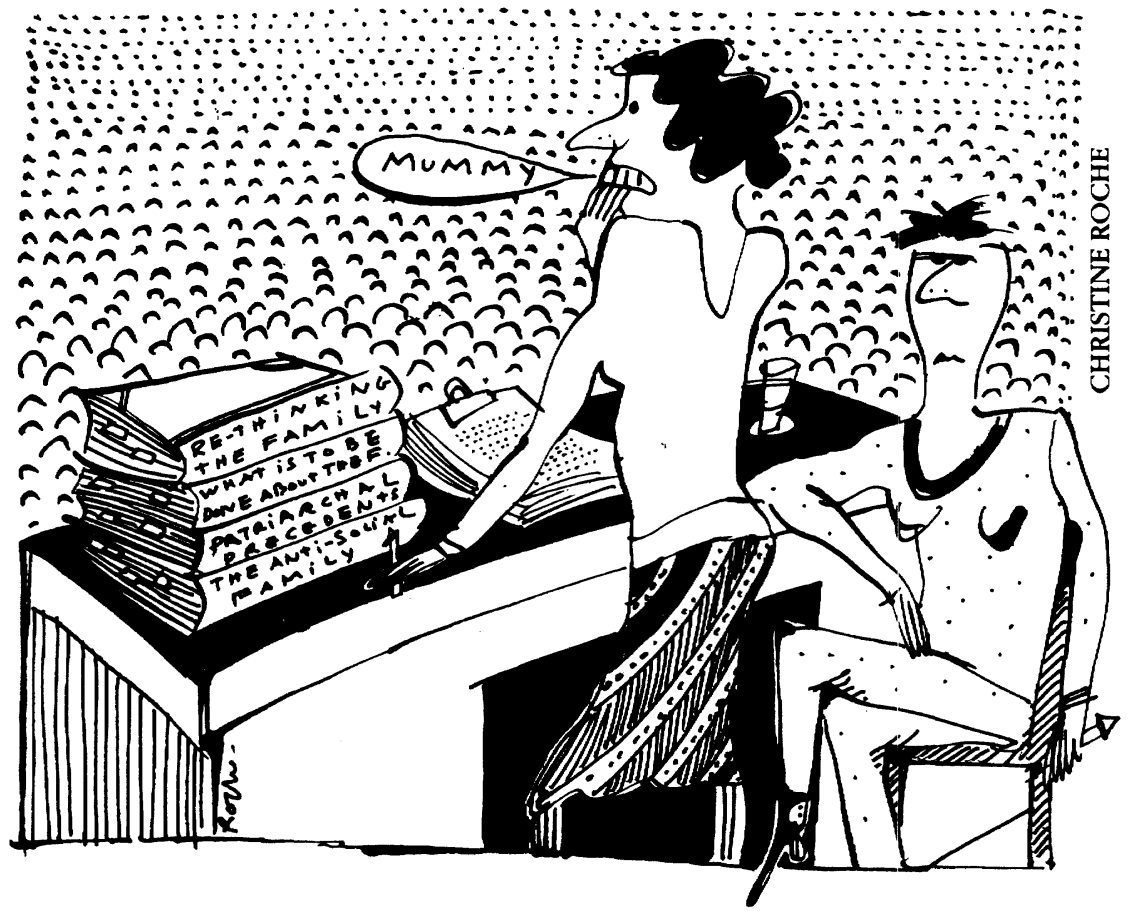

and continues to find its referents in, an active engagement with the practical demands of feminist campaign politics and with a theoretical awareness that the issues are by no means straightforward.

But the US collection may also be seen as confronting accepted and dominant modes of discussing the relations between the sexes, extending existing knowledges within specific academic accounts and generally mounting a form of critique that derives from the perspectives of feminism. As such it also claims a status as intervention, but an intervention into academic territory. But the unsatisfactoriness of some of the contributions in this volume is to be found in the models of explanation they employ and in their reproduction of dominant social-scientific understandings rather than their failure to adopt a 'feminist' stance. This means that it is not possible to detach the set of meanings that the use of the term 'feminist' has and judge these pieces solely by the criterion of their commitment to feminism (a criterion they all claim). I read these articles primarily in relation to their use of alreadly well-established methods of working and any judgments of them depend on my assessment of these first and foremost. Although there is no space to develop this here I think the process by which we decide that a piece of writing or any cultural product is 'feminist' is extremely problematic. Moreover it leads to the issue of whether or not it is possible, or even desirable to defend a 'feminist method'; but that goes beyond the scope of this review.

In pointing to sets of shared preoccupations and different scopes I am far from negating the interest or importance of the issues described. But I am insisting that there can be no fruitful discussion of the political projects of these books, or of how we are to evaluate them, without a recognition of the possible audiences/readers constructed by the issues raised and by how those issues are presented. This means acknowledging the limits of these projects and accepting them as necessary and productive. Within such a perspective all of these books may be seen as useful working texts with which we may proceed to examine more probingly the variety of practices alluded to here. 
What does not seem helpful is to argue for the books' similarities or to use the fact of their publication within a short space of time to back up assertions that they are really all dealing with the same thing. They can only be appropriated in this way by diminishing their differences in the interests of the kinds of banal generalizations about 'the family' that feminists, along with some other researchers, have been increasingly concerned to dispute. Nor does there seem very much to be said for conflating this series of concerns with the increased attention to 'the family' within conservative social movements and official politcal platforms. It is true, as I said earlier, that there is a lot of public visibility for questions relating to sexuality, and to forms of living. But without attention to the differences say, between the orchestration of moral panics around AIDS, the publication of a book like The Subversive Family, the kind of media attention to a royal baby and discussion of benefits for single mothers, we are left with a kind-of analysis that gives us nothing because of its tendency to see a very disparate set of practices subsumed under the one overarching umbrella.

What I am at some pains to labour here is that the different arguments of these books crystallize, rework and extend what have been and continue to be, the life and work preoccupations of particular groups of people - and they do this in different ways. For some of the issues presented here this means a life project; the sense of concern and commitment to be found in the Segal collection is, despite the brevity of the contributions, engaging. But it seems to me it is unnecessary to argue that many of the issues presented in this volume have a very wide currency and/or popular relevance. This does not mean that they are not important in themselves. But they are also important as signs of the multiplicity of ways the private and domestic spaces we inhabit have been interrogated and taken apart. In that process they have been revealed as the sites of a vast range of intersecting initiatives, both external and internal, as well as being the sites of very contradictory needs, desires and interests.

This opening up and elaboration is of vital political importance in itself, since for far too long the taken-for-grantedness of what happens within families and the assumed unity of interests to be found there has dominated most writing and talking about 'the private'. These initiatives all insist on the constructedness of that space as well as on the variety of practices, emotions, different ways of living given by such a cover-all term. I see opening this issue up as a political project in itself. It means that however we understand the relation between the dissemination of specific cultural practices and ideas, and the lived experience of the majority of families, there are now tools for posing questions differently, for posing different questions, for thinking the possibility that things could be and often are, otherwise. Such a contention does not ignore the differential experience of households pointed out by Rayna Rapp in Thorne and Yalom, (pages 168 onwards) or Barrett and McIntosh. It argues that each of these are phenomena to be considered and investigated in their own right, and further that it is through those investigations that we move forward.

Within a much more overtly scholarly but equally polemical set of questions Rosalind Coward's book offers a not dissimilar orientation from that outlined above. She argues that the way the problem of sexed subjectivities may now be approached depends on questioning and exposing the roots of past investigations and their continuing effects. Coward examines how many of our contemporary approaches to the questions that feminism has made into priorities originate in the development of a series of nineteenth-century discourses which took the divisions between women and men and debates about the status of women as important and requiring explanation. But, she argues that the explanations produced then and the way they continue to be utilized now really must be seen as part of the problem in that they either incorporate, or rely on, a series of links that need to be prised apart and questioned rather than assumed as the basis for a possible radical politics of sexual identities. 


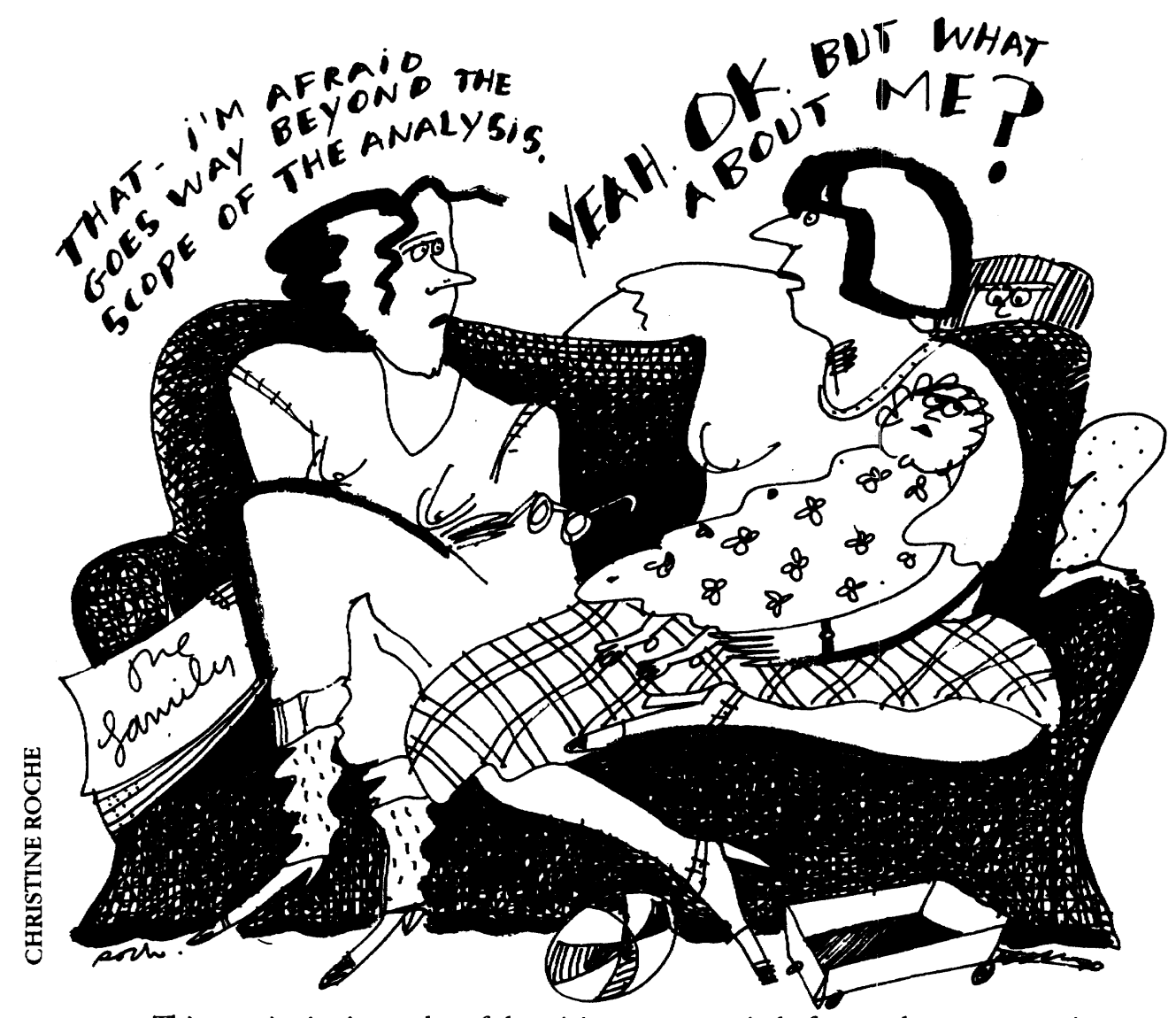

This continuity in modes of theorizing over a period of more than a century is organized around the idea of an evolutionist history of the family combined with the insistence that structures of sexual relations are to be understood by reference to that family. Coward wants to see how a study of sexual identities could proceed now through tracing the histories of nineteenth-century preoccupations but she is also using this instance, one that derives from the struggles of feminism and her commitment to it, as a way into a different set of debates. These are debates concerned with the dominant modes of explanation within the social sciences. Coward argues that these have depended either on a series of dualisms that privilege one or: other term of the individual/society dichotomy or they have argued that culture and cultural practices - and these include sex, sexuality, sexual relations, sexual identities - are determined by processes seen as external to them. Alternatively they are seen as the reflection of, or the key to, a series of histories that may all be linked up to give a tidy account of the social totality. Coward not only dismisses these forms of explanation as inadequate, but she insists that they are an integral part of much feminist concern with these issues. Assuch Coward considers them to have hampered these same investigations.

In re-examining the extended interest in debates about sexual relations in the latter half of the nineteenth century she uses a method that also considers the conditions in and through which such debates emerged, as the necessary context for placing what was being said. She argues that those discussions apparently organized around the problematic of the family, sexual relations, and marriage, were also about the socio-political developments of the period in that they regarded social and political alliances.

These debates were one focus for those nineteenth century accounts developing the specific domain of 'the social'. The book sets out some of the major debates and looks at how they were subsequently challenged first within anthropology, then by Marxism and by psychoanalysis. She argues that neither the anthropological challenge nor the discourses of Marxism or psychoanalysis escaped from the universalizing assumptions, both implicit and explicit, of these earlier debates, although the latter two posed the questions in a potentially more fruitful way. For instance, she points to the utilization of 
the concept of the patriarchal family as limiting the ways it was possible to present the specific issues regarding the status of women. Her account of Marxism's attention to the family theoretically and the implications of this for a politics of, and for, women is especially clear. Moreover it reveals the extent to which the way that the problem is posed has decided effects for the kinds of policies that are suggested by its emphases. This crucially leads on to present-day feminist struggles. It also argues against seeing debates about the forms of explanation in operation at any given time as of mere academic interest.

\section{Issues for feminists}

I now wish to return to the Segal collection, to point to some of the issues brought forward there that seem to me to be of interest. As I said earlier there is no way of dealing adequately with all of the themes presented in these books so I have selected some of the issues that I see as important.

Collier et al (in Thorne and Yalom p35) claim that 'we ideologize relations within the family as nurturant while casting relationships outside the family - particularly in the sphere of work and business - as just the opposite.' This connects to some of the most valuable insights in the Segal collection. For instance Mica Nava's article provides a resumé of early initiatives. She sees that the moves towards having men take responsibility in the house, the possibility of communal living and consciousness raising were the three key features for feminist politics. Wendy Clarke wants to acknowledge the real gains that feminists have made in making the oppressive aspects of 'the family' visible but to insist on the ideological hold that the idea of the family exerts so that we continue to long for certain things about it even when we know the reality of its oppressiveness. She sees feminism as primarily having concentrated on 'the visibly oppressive nature of the family' and, all in all to have dealt with this relatively successfully. But what about 'the less tangible' aspects of the family, what about our desire for a home that will encapsulate all those wants which the family claimed to be able to satisfy? Clarke brings forward questions that urgently require work at levels beyond those that are dealt with in campaigning against the oppressiveness of family structures. It is not that the latter is unimportant; but she is saying that some things continue to elude us in this politics.

What feminists also know is that sexual matters, power, jealousy, commitment, fatherhood, security, autonomy, and growth are seldom as open to negotiation and analysis. Are these such overwhelming problems for us that it seems a defeat even to be drawn into discussing this aspect of family? ( 173 )

People continuing to go home for Christmas or seeing coming out to their parents as of a different order from coming out to anyone else may seem obvious examples. But Clarke is suggesting that the reasons they continue to be areas of importance and difficulty have not been talked through enough; such things are part of what it means to opt for apparently 'alternative' family forms and household arangements when we also bring with us the continuing resonances, not just of our own family experiences but the purchase on us that the familialization of the culture we inhabit continues to have.

The problems that have emerged in collective living situations point to how, in attempting to escape from the oppressiveness of family life, we can often only reproduce some of the more mechanical ways in which the patterns of familial arrangement can be subverted, leaving unapproached the murky areas of the contradictory desires for permanence and difference, of safety but not suffocation. I think it is not so much that we leave them on one side. Rather that it is only by trying different ways, by arguing for and having won certain things that may now seem mechanical or routine that we have the space to recognize the contradictoriness that Clarke wants to highlight. That is, it again 


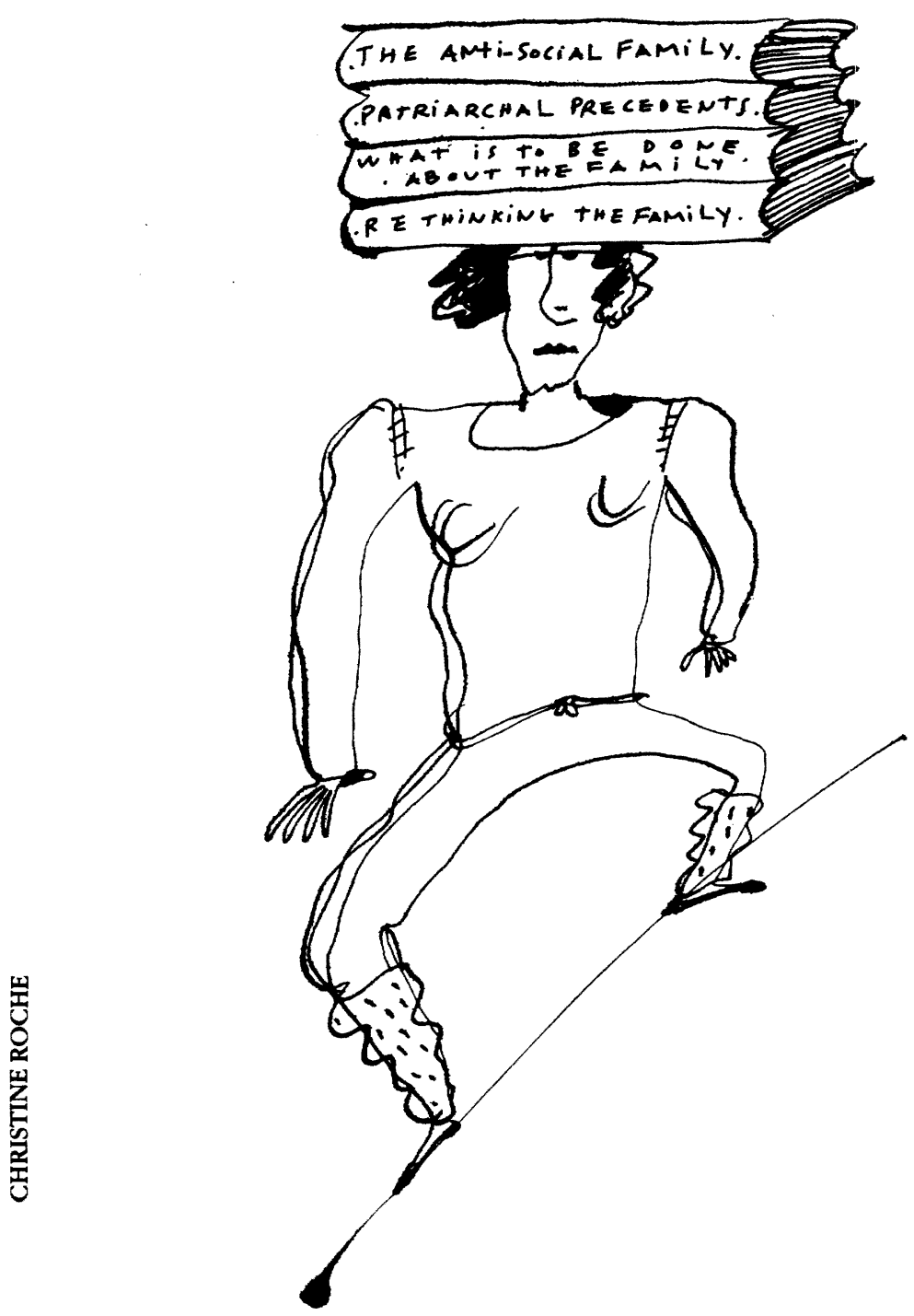

becomes a question of using the experience of the past to build a future that recognizes the absences of that past but which could not be conceived without the learning process of the attempts of the last years. Brecht once said 'don't start from the good old things but the bad new ones' (Benjamin, 1973). With such a perspective it becomes fruitful to examine further some of the areas that have emerged; for example, the possibilities for emotional support in an extended network of people and how this is counteracted by sexual relationships; the extent to which the new forms of household act as a factor of exclusion for others who are brought into them but do not 'belong'; the inability to deal with sexual relationships in these households as a real parallel to the secrecy through which sex is generally situated - that is as an absence - in regular families; the taking on of family positions among the collective members and their potential oppressiveness; the turnover rate, the lack of permanence and the fears that such changes highlight. Clarke poses the problems of the discrepancies between how we want to live and what is possible for us, and in so doing highlights areas of vital importance. 
In a piece that may profitably be read in conjunction with this one Denise Riley makes problematic another aspect of familial relationships - those between mothers and children. She emphasizes how relations between mothers and children have been problematic for feminism since they devolve around questions of differential need across the generations and contradictions in the experience of motherhood itself. 'The creative aspects of motherhood are celebrated again . . . and in a way that is quite right; but is not an interesting or encouraging kind of rightness. It tells us what we already know: that there are passions and surprises bound up with childcare as well as the exhaustion and isolation dwelt on by women's liberation' (p. 137). How can feminism both support women's desires to be mothers and argue for those desires being understood differently when motherhood is so centrally available, and has increasingly been so throughout the twentieth century, as a centre of conservative (and naturalizing) ideologies? Like Wendy Clarke, Denise Riley insists on the limits of feminist theorizing and demands. She wants to expose the difficulties in conceiving what a feminist account of childcare could be, and indeed wants to question whether speaking as if one were possible makes sense at all. She singles out two areas. The first is thinking about childcare vis-à-vis local and central state agents and institutions - how demands are to be posed and what we would want were childcare to be available. The second is the demand for shared parenting. Both of these have been planks of feminist initiatives around childcare and both raise questions of differential needs. She wants to emphasize the tendency to individualist solutions implied in some accounts of joint parenting and to say that such moves lose sight of all those who are not in a position to allow it. These include couples where the externally structured inequalities of the division of labour mean that really shared parenting is a financial impossibility; and also single parents.

Although Riley does not say that they are necessarily posed as alternatives, I think she does imply that we tend to agitate for, or settle for, one or the other as a goal shared parenting or increased community provision. Possible forms of community provision return us to the essentially regulated aspects of familial relations and to the way the different needs that occur generationally, and between genders, if pushed to their extreme are resolved by recourse to external agencies, the courts, the welfare services, and so on. How do you, she asks, estimate the desires of the child for security and harmony and those of mothers for sexual expression (p. 139)? The sexualized mother may provide an instance where the state steps in. To say this is to say something about the state and something about mothers.

The family-state relation is a central theoretical consideration that recurs in all of these books. The conception of 'the family' as ever having been a haven, free from the intervention and intrusions of the outside world is a myth increasingly disputed by the growing body of literature on the growth in the state itself as well as the feminist concern with the family-women-state links. In the overview of Zaretsky, and less historically, Segal; in Barrett and McIntosh's engagement with Donzelot (and other, more local references); in Riley's questions about forms of childcare; in Bennett's account of the implications of feminist slogans like 'disaggregate now', the issue is variously addressed.

How impossible it is (or indeed ever was) to ignore the role of the state in the constitution of families is something all these books acknowledge either implicitly or explictly. But it is not just a matter of the distinctions between different benefits and how they are allocated or the implications of the recourse to external experts in decisions about the custody of children or the distribution of joint property. Rather what becomes central is the increasingly active role of 'the state' in constructing the boundaries by which we even begin to understand how 'the family' means different experiences for different class and gender groups. This points to the way the personal, 
the alleged private, is criss-crossed by areas seen as outside it and as such is a deeply ideological construct. Elaborating and developing these links seems to be one vital continuing area of feminist work.

Another general area informing several of the contributions - Nava, Campbell, Barrett and McIntosh - is that of moralism and censure within and between feminists. The impossibility of any unitary feminism that presents the right way to live, to conduct our sexual relationships, live our sexual preferences, choose our interests and choose the ways we approach our work, has been a problem and continues to be one. In the situation of an increasingly differentiated set of perspectives, goals, work options and styles of living, these stands require analysis. These issues of moralism and evaluation within feminism also refer back to the questions of the kinds of styles and approach that are endorsed in the four books under review. There is a very real sense in which a different but identifiably similar form of moralism operates in regard to questions of academic style and accessibility. Often a kind of argument is put forward to sustain the view that 'feminist' equals 'accessible', or 'has to be understood by everyone at a first reading'. These books use different styles, different forms of address and different methods, though sometimes the issues are the same. Despite this I would argue that their potential reader would primarily be drawn from similar sets of women and men having an engagement with feminism and socialism. Not all of these approaches will be similarly estimated by all of these readers but there will be a degree of overlap. It amounts to another form of moralism to see some of the issues or approaches under discussion as more relevant to real everyday concerns than others in any absolutist sense. For such a position assumes that what is real and important is self-evident and to be taken for granted. Issues that manifest themselves in where and how we work, and where and how we live are variously addressed in the work of these feminists. At the same time the range of relations and practices that are subsumed within the concept of 'the family' and the kinds of books written using the concept as guiding thread emphasize its inadequacy as a satisfactory encapsulation. It is a matter of some importance that the range and variety of practices and relations referred to here are given attention for the separate if related histories they establish and distill. For me that requires work in a series of very different contexts and the agreement that feminism has provided reasons for that work being seen as relevant, important and ongoing.

\section{Note}

Lesley Caldwell is a member of the Feminist Review collective and works at the Institute of Education in London. At the moment, she is researching the state regulation of motherhood in Italy.

\section{Reference}

BENJAMIN, Walter ( 1973) Understanding Brecht. New Left Books. 